\title{
The problem of head and neck cancer and its treatment
}

\begin{abstract}
The oral cancer is predominant in developing countries, particularly in lower socioeconomic sectors. Surgery, radiotherapy and chemotherapy are the therapeutic modalities used in the treatment of head and neck cancer. They can be used alone or together. Radiation therapy causes lesions in normal tissues located in the radiation field. The resulting oral sequelae can cause substantial problems during and after radiation therapy and are the major determining factors in patients' quality of life. The most serious and debilitating complications of radiotherapy are mucositis candidiasis and osteoradionecrosis.
\end{abstract}

Keywords: head and neck neoplasms; radiotherapy; chemotherapy
Volume 9 Issue 2 - 2018

\section{Igor Figueiredo Pereira}

'Oral and Maxillofacial Surgeon, Federal University of Minas Gerais, Brazil

${ }^{2}$ Master in Dentistry, Federal University of Minas Gerais, Brazil ${ }^{3} \mathrm{PhD}$ student in Oral Maxillofacial surgery, University of Pernambuco, Brazil

Correspondence: Igor F Pereira, Department of Prosthodontics and Bucco Facial Surgery, University of Pernambuco,Av. Gal. Newton Cavalcanti, 1650, Tabatinga, Camaragibe, PE, 54756-220, Brazil,

Email: figueiredo.ctbmf@gmail.com

\section{Introduction}

The number of cancer cases has increased considerably worldwide and is now one of the most important public health problems in the world. Oral cancer has a predominance in developing countries, especially in a population with lower socioeconomic levels. ${ }^{1}$ Most of these patients are dependent on the public health system, where a delay in care can occur, thus favoring a late diagnosis, whose treatment is more aggressive, with an unfavorable prognosis, Which reduces their quality of life and increasing mortality rates. ${ }^{2}$ Smoking and alcohol abuse are well-known risk factors for the development of oral cancer. Currently the total amount and time of alcohol consumption have been considered more important than the type of alcoholic drink ingested. ${ }^{3,4}$

\section{Mini review}

Treatment of the patient with oral cancer involves a multidisciplinary team that must work integrated aiming the elimination of the disease, while maintaining the quality of life of the patient.. High doses of radiation in extensive fields leave several complications that significantly affect patients' quality of life. In addition, these complications can affect even the course of treatment. So we can quickly cite and define the main complications of radiotherapy and chemotherapy for head and neck cancer. ${ }^{6}$

\section{Mucosistis}

Mucositis is a mucosa lesion with a complex pathogenesis. It is one of the most significant and common complications in cancer patients who are submitted to radiotherapy or Chemotherapy and even in combination therapy. ${ }^{7-9}$ Mucositis is a complication due to xerostomia, caused by the hypo function of the salivary glands altered by irradiation, which can cause painful and debilitating adverse effects, such as severe pain and difficulty in feeding and maintaining hygiene, which may occur during and after treatment, in turn compromising one's Quality of Life and potentially increasing patient mortality. ${ }^{10,11}$

\section{Candidiasis}

Candida albicans and related fungi are commensal organisms that routinely inhabit the oral cavity. Under normal circumstances they co-exist with the other oral microorganisms of the oral cavity and do not cause disease. Colonization and infections do occur under circumstances where the systemic or local environments altered, including the immunosuppression, hyposalivation, tissue damage, and / or imbalance of flora observed in cancer patients undergoing treatment of head and neck radiotharapy. ${ }^{12}$

\section{Dental disease}

Few clinical studies have examined the impact of cancer therapies on dental disease such as caries and periodontal disease. A report said that the weighted prevalence of dental infections abscesses during chemotherapy is approximately $6 \% \cdot{ }^{13}$ Patients who had undergone radiotherapy for head and neck malignancies had the highest rate of decayed missing filled teeth among patients who have had antineoplastic therapies. ${ }^{14}$

\section{Osteoradionecrosis (ORN)}

One of the most serious complications of head and neck radiotherapy and is considered a public health problem worldwide. It is characterized by defects in healing and the loss of bone viability, induced by the tissue effects of radiation. ${ }^{15}$ Osteoradionecrosis of the jaws is, undoubtedly, one of the major complications of radiotherapy in the head and neck region and cannot always be avoided, generating a huge psychological and physical impact on patients. ${ }^{16}$

\section{Conclusion}

It is extremely important that all healthcare professionals involved with these patients be able to diagnose complications arising from the antineoplastic treatment. Extensive professional support will provide the patient with greater confidence and cooperation that will positively reflect in the final treatment outcome. ${ }^{6}$ 


\section{Acknowledgement}

None.

\section{Conflict of interest}

None.

\section{References}

1. Torres Pereira C. Oral cancer public policies: is there any evidence of impact? Braz Oral Res. 2010;24(1):37-42.

2. Ribeiro IL, Medeiros JJ, Rodrigues LV, et al. Factors associated with lip and oral cavity cancer. Rev Bras Epidemiol. 2015;18(3):618-629.

3. Salarić I, Povrzanović I, Brajdić D, et al. Potentially malignant oral disorders and Highrisk habits in liver cirrhosis and lung cancer patients. Oral Dis. 2015;21(3):373-377.

4. Park B, Kong SY, Kim J, et al. Health Behaviors of Cancer Survivors in Nationwide CrossSectional Survey in Korea: Higher Alcohol Drinking, Lower Smoking, and PhysicalInactivity Pattern in Survivors with Higher Household Income. Medicine (Baltimore). 2015;94(31):1-8.

5. Rathod S, Livergant J, Klein J, et al. A systematic review of quality of life in head and neck cancer treated with surgery with or without adjuvant treatment. Oral Oncol. 2015;15(10):888-900.

6. Lambrecht M, Mercier C, Geussens Y, et al. The effect of a supersaturated calcium phosphate mouth rinse on the development of oral mucositis in head and neck cancer patients treated with (chemo) radiation: a singlecenter, randomized, prospective study of a calcium phosphate mouth rinse + standard of care versus standard of care. Support Care Cancer. 2013;21(10):2663-2670.

7. Vadhan Raj S, Goldberg JD, Perales MA, et al. Clinical applications of palifermin: amelioration of oral mucositis and other potential indications. J Cell Mol Med. 2013;17(11):1371-1384.
8. Patussi C, Sassi LM, Munhoz EC, et al. Clinical assessment of oral mucositis and candidiasis compare to chemotherapic nadir in transplanted patients. Braz Oral Res. 2014;28:1-7.

9. Plemons JM, Al-Hashimi I, Marek CL. American Dental Association Council on Scientific Affairs. Managing xerostomia and salivary gland hypofunction: executive summary of a report from the American Dental Association Council on Scientific Affairs. J Am Dent Assoc. 2014;145(8):867-873.

10. Mosel DD, Bauer RL, Lynch DP, et al. Oral complications in the treatment of cancer patients. Oral Dis. 2011;17(6):550-559.

11. Hanchanale S, Adkinson L, Daniel S, et al. Systematic literature review: xerostomia in advanced cancer patients. Support Care Cancer. 2015;23(3):881-888.

12. Sroussi HY, Epstein JB, Bensadoun RJ, et al. Common oral complications of head and neck cancer radiation therapy: mucositis, infections, saliva change, fibrosis, sensory dysfunctions, dental caries, periodontal disease, and osteoradionecrosis. Cancer Med. 2017;6(12):2918-2931.

13. Hong CH, Napenas JJ, Hodgson BD, et al. A systematic review of dental disease in patients undergoing cancer therapy. Support Care Cancer. 2010;18(8):1007-1021.

14. Rautemaa R, Lauhio A, Cullinan MP, et al. Oral infections and systemic disease - an emerging problem in medicine. Clin Microbiol Infect. 2007;13(11):1041-1047.

15. Omolehinwa TT, Akintoye SO. Chemical and Radiation-Associated Jaw Lesions. Dent Clin North Am. 2016;60(1)265-277.

16. He Y, Liu Z, Tian Z, et al. Retrospective analysis of osteoradionecrosis of the mandible: proposing a novel clinical classification and staging system. Int J Oral Maxillofac Surg. 2015;44(12):1547-1557. 